\title{
Formation mechanism of core-shell nanocrystals obtained via dehydration of coprecipitated hydroxides at hydrothermal conditions
}

\author{
O. V. Almjasheva ${ }^{1,2}$, A. A. Krasilin ${ }^{2}$, V. V. Gusarov ${ }^{2}$ \\ ${ }^{1}$ Saint-Petersburg Electrotechnical University "LETI", Saint-Petersburg, 197376 Russia \\ ${ }^{2}$ Ioffe Institute, Saint-Petersburg, 194021, Russia \\ almjasheva@mail.ru, ikrasilin@mail.ioffe.ru, victor.v.gusarov@gmail.com
}

DOI 10.17586/2220-8054-2018-9-4-568-572

Here, we propose a formation mechanism for core-shell nanoparticles by self-organization in coprecipitated mixed hydroxides under hydrothermal conditions. A thermodynamic reason for this process is because of a decrease in the components' solubilities together with an increase of structure's dimension. As a particular example of such type of behavior, we investigate core-shell nanoparticle formation in the $\mathrm{ZrO}_{2}-\mathrm{Y}_{2} \mathrm{O}_{3}-\mathrm{H}_{2} \mathrm{O}$ system.

Keywords: core-shell nanoparticles, hydrothermal synthesis, multi-component systems, solid solution, zirconia, formation mechanism.

Received: 16 August 2018

\section{Introduction}

Core-shell nanoparticles have garnered substantial interest due to the potential of their application in the field of biomedicine [1-3], catalysis [4,5], sensorics [6,7], luminophores [8], and materials for optics [9, 10]. A large number of papers [1-12], that have been published recently, cover aspects of chemical synthesis, structure and properties investigation of the nanoparticles.

There are two means of core-shell nanoparticle synthesis. The first one includes various types of application of the nanosized layers on the initial nanoparticle surface. This can be done by precipitation from a gaseous phase, for example, by CVD, PVD, ALD (ML) methods [12-17]; or by precipitation from a liquid phase by SILD and LbL methods $[18,19]$. Layers and shells can be obtained by transport from one particle to another [20-23] as a result of non-autonomous (surface) phase movement [23]. However, this group of methods is not limited to the aforementioned techniques.

Another group relies on the effect of substance segregation inside the particle with redistribution of the components between the volume and the surface [24-26]. Despite the fact that the thermodynamic theory describing the component redistribution between autonomous (volume) and non-autonomous (surface) phase is welldeveloped [27], in certain cases there is a dramatic discrepancy between experimentally observed effects and their thermodynamic predictions. Among these problems, there is a case of substantial difference between the measured shell thickness, obtained after the segregation, and the equilibrium thickness of the non-autonomous phase [28]. In particular, this feature was observed for oxide nanoparticles in $\mathrm{ZrO}_{2}-\mathrm{Y}_{2} \mathrm{O}_{3}-\mathrm{H}_{2} \mathrm{O}$ (M=Y, In, Gd) system [25, 26], produced by the hydrothermal treatment of coprecipitated hydroxides.

The aim of this work is to model processes which lead to the formation of core-shell structures through decomposition of initial substances and formation of nanoparticles - nuclei for the new nanostructured phase.

\section{Model}

Let us consider the case, in which initial substance forms quasi-2D layers of variable composition situated some substantial distance from each other and randomly oriented. In such a manner, chemical composition, structure, and properties do not depend on the layers' relative position. Distancing of quasi-2D layers owes to adsorption of molecules on their surface and their immersion into an isotropic medium, for example, water. Removal of adsorbates or liquid environment between the layers initiates distance decrease in between them. In turn, this leads to the layers' rearrangement, correlation in their structural changes and, as a consequence, their properties. In such a manner, 3D particles can be formed involving oriented attachment mechanism [29-32]. Fig. 1 shows the transformations described above. Let us assume that quasi-2D layers are of nanometer or sub-nanometer thick, and the width of layers is at least in order of magnitude larger that the thickness. At the same time, the width stays in nanometer scale, so the particles formed in oriented attachment process can be considered as nanoparticles. For the sake of simplicity, but without loss of generality of principle derivations, present research focuses on transformations occurring in binary solid solutions. 


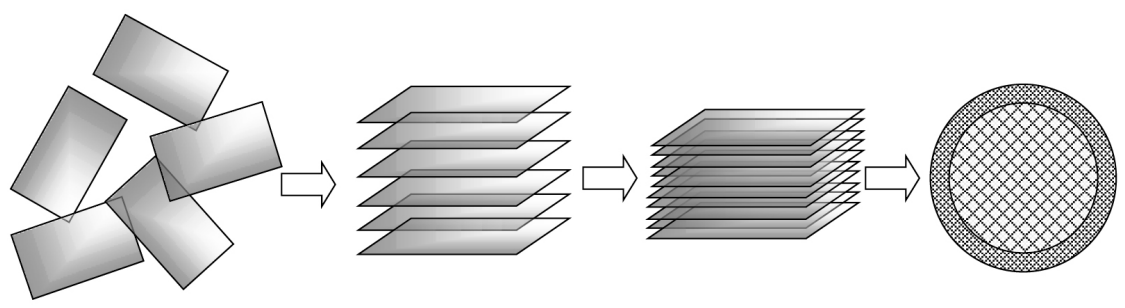

FIG. 1. Scheme of formation of $\mathrm{c}-\mathrm{ZrO}_{2}\left(\mathrm{Y}_{2} \mathrm{O}_{3}\right)$ nanoparticles during dehydration of coprecipitated hydroxides under hydrothermal conditions

For the case of two-component phases of variable composition and different dimension, the Gibbs energy of mixing is:

$$
G^{(\nu) M}=G^{(\nu) E X}\left(x_{1}, x_{2} ;\left\{a_{i}\right\}\right)-T S^{(\nu) I D}\left(x_{1}, x_{2}\right),
$$

where $x_{1}, x_{2}=1-x_{1}$ are molar contents of components 1 and $\mathbf{2}$ in phases of variable composition; upper index $\nu=1,2,3$ shows dimension of corresponding phases: $\nu=1$ is for quasi-1D, $\nu=2$ is for quasi- $2 \mathrm{D}$, and $\nu=3$ is for $3 \mathrm{D}$ one (in general, $\nu$ can be non-integer denoting structures with certain fractal dimension); $T$ is temperature, $\mathrm{K} ; S^{(\nu) I D}$ is configuration entropy of ideal state [33]; $G^{(\nu) E X}\left(x_{1}, x_{2} ;\left\{a_{i}\right\}\right)$ is the excess Gibbs energy of mixing determined by configuration entropy of ideal state; and $\left\{a_{i}\right\}$ is a number of parameters included in model equations [33]. For the most basic case of ideal mixture of components 1 and $2 S^{I D} \equiv S^{I}=-R\left(x_{1} \ln x_{1}+x_{2} \ln x_{2}\right)$. For the case $S^{I D} \equiv S^{I} G^{E X} \equiv G^{E}$, i.e. the equation (1) coincides with the commonly used equation for the excess Gibbs energy of mixing: $G^{E}=G^{M}+T S^{I}$.

It can be further simplified by assuming that $S^{I D}=S^{I}$. In making this assumption, the difference between the ideal entropy $\left(S_{I}\right)$ and configuration entropy of the proposed idealized state, which would, probably, better reflect the state of variable composition $\left(S^{I D}\right)$, transfers to the value $G^{E}=G^{E X}+T\left(S^{I}-S^{I D}\right)$. One should expect to see the highest difference between the $S^{I}$ and $S^{I D}\left(G^{E}\right.$ and $G^{E X}$, correspondingly) values in case the phase of variable composition is formed by components with different oxidation states [33,34], because this leads to formation of defects like vacancies or ions in the interstitial space of the crystal lattice.

The 1D solid solution $(\nu=1)$, as it was shown in [35], withholds from segregation at any temperature: this means that $G^{E}=0$. Urusov [34] noted that the $G^{(2) E}$ value for quasi-2D structures is several times smaller than the $G^{(3) E}$ value for the 3D ones. One can conclude that the solid solution components solubility decreases with increase of the structure dimension (1D to 3D). There is a probability that, during the nanoparticle growth, the substance separated out of solid solution will form the shell on the particle surface. Next, we consider the possibility of the core-shell structure formation involving the proposed mechanism during dehydration in $\mathrm{ZrO}_{2}-\mathrm{Y}_{2} \mathrm{O}_{3}-\mathrm{H}_{2} \mathrm{O}$ system.

\section{Results}

Degtyarev and Voronin [36] calculated the thermodynamic parameters of coexisting phases in the $\mathrm{ZrO}_{2}-\mathrm{Y}_{2} \mathrm{O}_{3}$ system. Dehydration of coprecipitated zirconium and yttrium hydroxides yields oxide nanoparticles with fluorite structure, which is characteristic for the high-temperature area of the $\mathrm{ZrO}_{2}-\mathrm{Y}_{2} \mathrm{O}_{3}$ phase diagram. Thus, we used high-temperature data for thermodynamic analysis of low-temperature area of the phase diagram according to adopted equations proposed by Degtyarev and Voronin in [36]:

$$
\begin{gathered}
G^{E X}=x_{1}\left(1-x_{1}\right) C\left(A_{0}+A_{1} T+B_{0} x_{1}\right), \\
S^{I D}=-R\left[2\left(1-x_{1}\right) \ln \left(1-x_{1}\right)+3 x_{1} \ln x_{1}+\left(4-x_{1}\right) \ln \left(4-x_{1}\right)-4\left(1-x_{1}\right) \ln 4-3 x_{1} \ln x_{3}\right],
\end{gathered}
$$

where $x_{1}$ is molar content of $\mathrm{YO}_{1.5} ; R=8.31$ is the gas constant, $\mathrm{J} /(\mathrm{mol} \cdot \mathrm{K}) ; A_{0}=-13273 R, A_{1}=5.324 R$, and $B_{0}=12383 R$ are numerical parameters; $C^{(\nu)}=0 . .1$ is a structure dimension depended coefficient.

Extrapolation of these data to the low-temperature area allows one to predict phase separation limits in cubic metastable phases in the $\mathrm{ZrO}_{2}-\mathrm{Y}_{2} \mathrm{O}_{3}$ system (Fig. 2a, curves 1). An over-estimation of the limits in comparison to the experimental results [25] can be related with the extrapolation error. Since the $\mathrm{Zr}_{1-x} \mathrm{Y}_{x} \mathrm{O}_{2-0.5 x}$ nanocrystals grow from quisi-2D fluorite-like layers [29] during the dehydration, the yttrium content in the initial quasi-2D layer should be substantially higher than that in the $3 \mathrm{D}$ phase. Fig. $2 \mathrm{~b}$ shows curves of $\mathrm{ZrO}_{2}-\mathrm{Y}_{2} \mathrm{O}_{3}$ solid solution decomposition calculated in accordance with the assumption of the Gibbs energy decrease with decrease of the phase dimension $(\nu=3 \rightarrow \nu=2)$, which is equal to decrease of the coefficient $C^{(\nu)}$ in (2). 


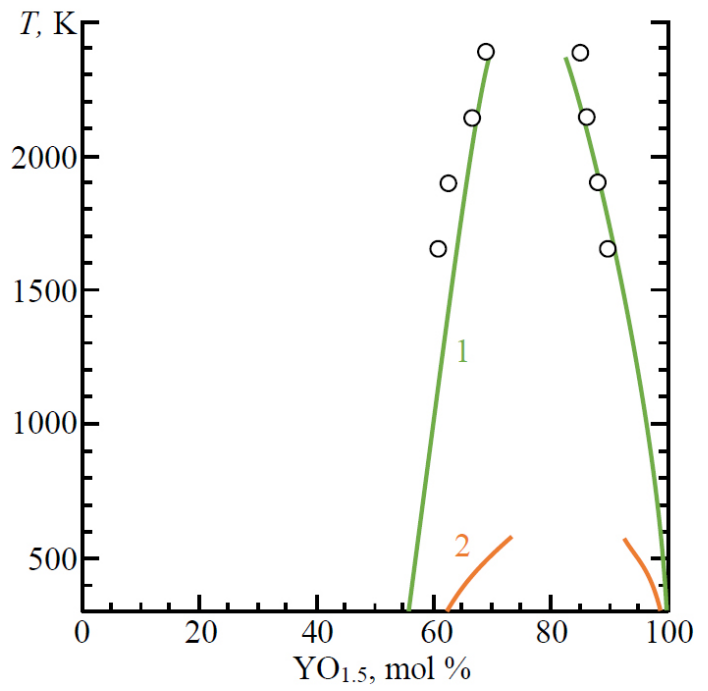

$a$

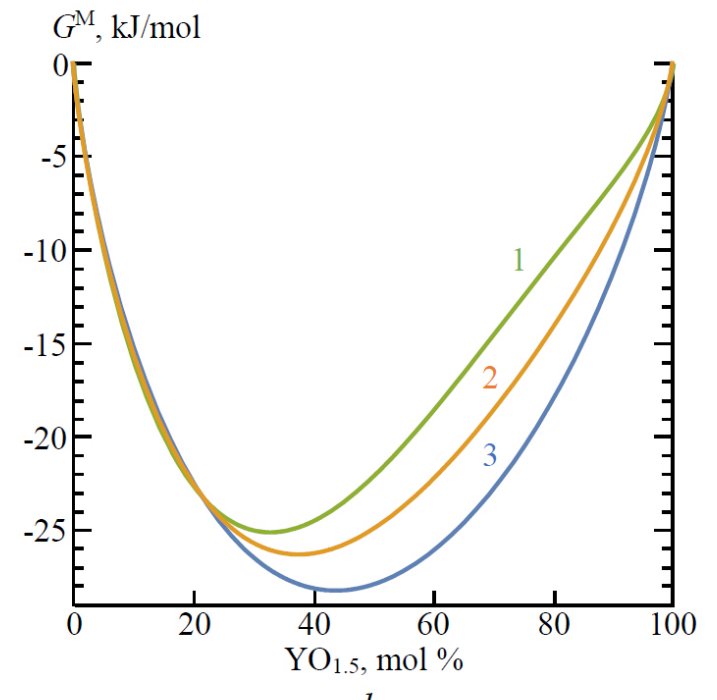

b

FIG. 2. a) Part of the $\mathrm{ZrO}_{2}-\mathrm{YO}_{1.5}$ calculated phase diagram. Points denote experimental data adopted from the paper [36]. Curve 1 was calculated at $C^{\nu}=1$, curve 2 was calculated at $C^{\nu}=0.6$ (see equations (2) and (3)). b) The Gibbs energy of mixing $G^{M}$ at $1-C^{(\nu)}=1,2-$ $C^{(\nu)}=0.6,3-C^{(\nu)}=0.2$

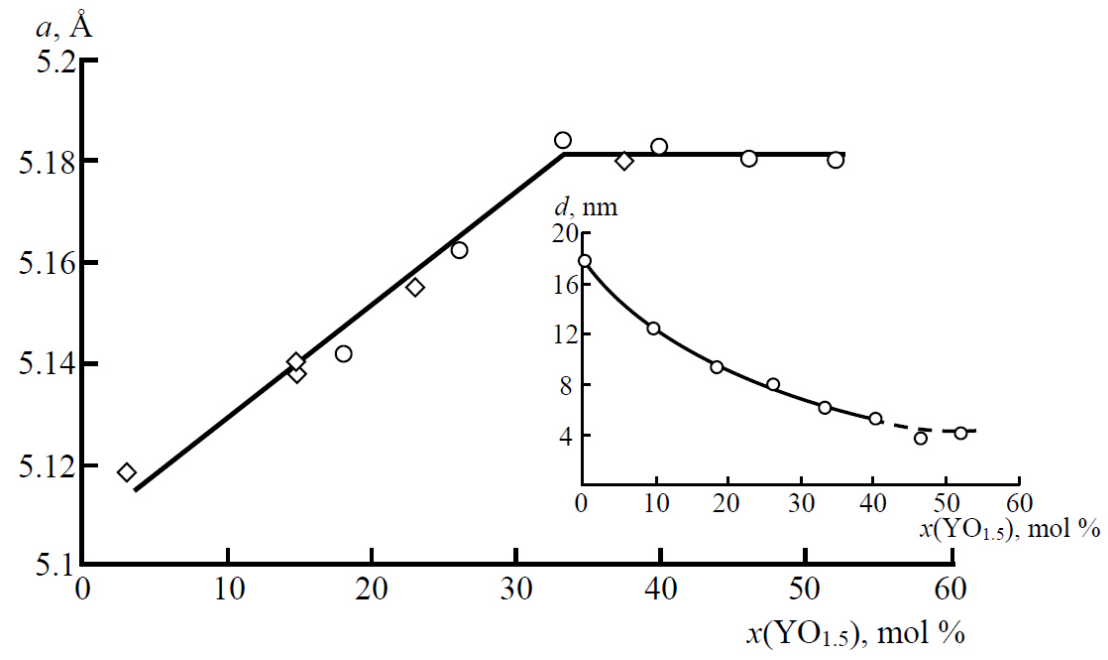

FIG. 3. Dependence of the parameters of the unit cell of the phase based on $\mathrm{c}-\mathrm{ZrO}_{2}$ with the fluorite structure on the content of $\mathrm{YO}_{1.5}$ in the system. The inset: the dependence of the crystallite size of $\mathrm{c}-\mathrm{ZrO}_{2}$ on the $\mathrm{YO}_{1.5}$ content

Summarizing the results for the thermodynamic analysis of the dimensions of the regions where solid solutions exist in quasi-2D and 3D phases, we conclude that, in the formation of nanocrystals based on phases of variable composition, by fusion of quasi-2D layers of variable composition, the solid solution can split into two coexisting phases. If the amount of matter released is not sufficient to form a crystalline nucleus of a new phase, it is possible to form core-shell structures, as shown on Fig. 1. Almjasheva et al. [25] showed that the "crystal c- $\mathrm{ZrO}_{2} / \mathrm{YO}_{1.5}$ fluorite solid solution core - amorphous $\mathrm{Y}_{2} \mathrm{O}_{3}$ shell" particles were formed in the $\mathrm{ZrO}_{2}-\mathrm{Y}_{2} \mathrm{O}_{3}-\mathrm{H}_{2} \mathrm{O}$ system under hydrothermal conditions. The results of the nanoparticles' composition and size parameters analysis (Fig. 3,4) demonstrate qualitative correlation with the thermodynamic data on the change in the solubility of components during the transition from quasi-2D to $3 \mathrm{D}$ structures. It should be noted that this explanation is, most likely, also applicable for the case of core-shell nanoparticles formation in another $\mathrm{ZrO}_{2}-\mathrm{M}_{2} \mathrm{O}_{3}-\mathrm{H}_{2} \mathrm{O}$ systems $\mathrm{M}-\mathrm{In}$, Gd) $[25,26]$. 


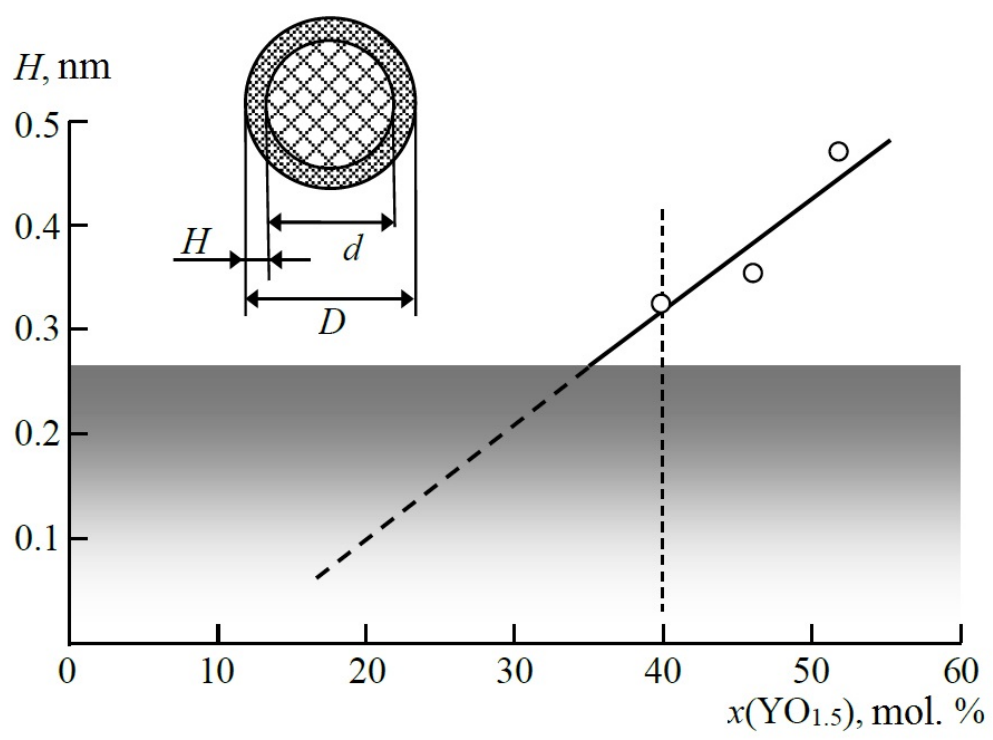

FIG. 4. Dependence of the thickness of the amorphous shell on the content of $\mathrm{YO}_{1.5}$ in the system

Thus, the mechanism for the formation of core-shell nanostructures (Fig. 1) by decreasing the mutual solubility of the components with increase of the structure dimension can be considered as one of the more promising means of such nanoparticle design.

\section{Acknowledgement}

The research was supported by Russian Science Foundation grant 16-13-10252.

\section{References}

[1] Chatterjee K., Sarkar S., Rao K.J., Paria S. Core/shell nanoparticles in biomedical applications. Adv. Colloid Interace Sci., 2014, 209, P. 8-39.

[2] Almjasheva O.V., Garabadzhiu A.V., Kozina Yu.V., Litvinchuk L.F., Dobritsa V.P. Biological effect of zirconium dioxide-based nanoparticles. Nanosyst.: Phys. Chem. Math., 2017, 8(3), P. 391-396.

[3] Rosenholm J.M., Zhang J., Sun W., H. Gu Large-pore mesoporous silica-coated magnetite core-shell nanocomposites and their relevance for biomedical applications. Microp. Mesop. Mater, 2011, 145(1-3), P. 14-20.

[4] Lee C., Shin K., Lee Y.J. Jung C. Lee H.M. Effects of shell thickness on Ag-Cu $\mathrm{O}_{2} \mathrm{O}$ core-shell nanoparticles with bumpy structures for enhancing photocatalytic activity and stability. Catalysis Today, 2017, 303, P. 313-319.

[5] Gawande M.B., Goswami A, Asefa T., Guo H., Biradar A.V., Peng D.-L., Zboril R., Varma R.S. Core-shell nanoparticles: synthesis and applications in catalysis and electrocatalysis. Chem. Soc. Rev., 2015, 44(21), P. 7540-7590.

[6] Khoshroo A., Hosseinzadeh L., Sobhani-Nasab A., Rahimi-Nasrabadi M., Ehrlich H. Development of electrochemical sensor for sensitive determination of oxazepam based on silver-platinum core-shell nanoparticles supported on graphene. J. Electroanal. Chem., 2018, 823, P. 61-66.

[7] Majhi S.M., Naik G.K., Lee H.-J., Song H.-G., Lee C.-R., Lee I.-H., Yu Y.-T. Au@NiO core-shell nanoparticles as a p-type gas sensor: Novel synthesis, characterization, and their gas sensing properties with sensing mechanism. Sens. Actuators B: Chem., 2018, 268, P. 223-231.

[8] Bugrov A.N., Smyslov R.Yu., Zavialova A.Yu., Kirilenko D.A., Pankin D.V. Phase composition and photoluminescence correlations in nanocrystalline $\mathrm{ZrO}_{2}: \mathrm{Eu}^{3+}$ phosphors synthesized under hydrothermal conditions. Nanosyst.: Phys. Chem. Math., 2018, 9(3), P. 378-388.

[9] Astafyeva L.G., Pustovalov V.K., Fritzsche W. Tuning light concentration inside plasmonic core-shell nanoparticles during laser irradiation. Photonics Nanostruct., 2017, 26, P. 35-40.

[10] Li Y., Shao L., Zhong F., Ding P., Chu B. Luo F., Xu K., Zeng F., Du Y. Light control based on unidirectional scattering in metal-dielectric core-shell nanoparticles. Opt. Commun., 2018, 426, P. 483-489.

[11] Klekotka U, Piotrowska B., Satu-la D, Kalska-Szostko B. Modified ferrite core-shell nanoparticles magneto-structural characterization. Appl. Surf. Sci., 2018, 444, P. 161-167.

[12] Chaudhuri R.G., Paria S. Core/Shell nanoparticles: classes, properties, synthesis mechanisms, characterization, and applications. Chem. Rev., 2012, 112(4), P. 2373-2433.

[13] Srdić V.V.; Mojić B., Nikolić M., Ognjanović S. Recent progress on synthesis of ceramics core/shell nanostructures. Process. Appl. Ceram., 2013, 7(2), P. 45-62.

[14] Nomoev A.V., Bardakhanov S.P., Schreiber M., Bazarova D.G., Romanov N.A., Baldanov B.B., Radnaev B.R., Syzrantsev V.V. Structure and mechanism of the formation of core-shell nanoparticles obtained through a one-step gas-phase synthesis by electron beam evaporation. Beilstein J. Nanotechnol, 2015, 6, P. 874-880. 
[15] Gusarov V.V., Malkov A.A., Malygin A.A., Suvorov S.A. Thermally activated transformations of $2 \mathrm{~d}$ nonautonomous phases and contraction of polycrystalline oxide materials. Inorg. Mater, 1995, 31(3), P. 320-323.

[16] Gusarov V.V., Malkov A.A., Ishutina Z.N., Malygin A.A. Phase formation in a nanosize silicon oxide film on the surface of aluminum oxide. Tech. Phys. Lett., 1998, 24(1), P. 1-3.

[17] Krasilin A.A., Bodalyov I.S., Malkov A.A., Khrapova E.K., Maslennikova T.P., Malygin A.A. On an adsorption/photocatalytic performance of nanotubular $\mathrm{Mg}_{3} \mathrm{Si}_{2} \mathrm{O}_{5}(\mathrm{OH})_{4} / \mathrm{TiO}_{2}$ composite. Nanosyst.: Phys. Chem. Math., 2018, 9(3), P. 410-416.

[18] Korotcenkov G., Gulina L.B., Cho B.K., Han S.H., Tolstoy V.P. $\mathrm{SnO}_{2}$-Au nanocomposite synthesized by successive ionic layer deposition method: Characterization and application in gas sensors. Mater. Chem. Phys., 2011, 128(3), P. 433-441.

[19] Lee D.K., Song Y., Tran V.T., Kim J., Park E.Y., Lee J. Preparation of concave magnetoplasmonic core-shell supraparticles of gold-coated iron oxide via ion-reducible layer-by-layer method for surface enhanced Raman scattering. J. Colloid Interface Sci., 2017 , 499, P. 54-61.

[20] Gusarov V.V., Egorov F.K., Ekimov S.P., Suvorov S.A. Mossbauer study of kinetics of films state formation under the interaction of magnesium and iron oxides. Zhurnal Fizicheskoi Khimii., 1987, 61(6), P. 1652-1654 (in Russian).

[21] Gusarov V.V. Fast solid-phase chemical reactions. Russ. J. Gen. Chem, 1997, 67(12), P. 1846-1851.

[22] Gusarov V.V., Suvorov S.A. Transformations of nonautonomous phases and densification of polycrystalline systems. J. of Appl. Chem. of the USSR, 1992, 65(7), P. 1227-1235.

[23] Gusarov V.V., Popov I.Y., Flows in two-dimensional non-autonomous phases in polycrystalline systems. Nuovo Cimento Della Societa Italiana Di Fisica D, 1996, 18(7), P. 799-805.

[24] Almjasheva O.V., Gusarov V.V. The role of non-autonomous state in the formation of nanomaterials structure and properties. Ch. 13 in Nanomaterials: Properties and Potential Applications. Nauchnyi Mir, Moscow, 2014. P. 384-409 (in Russian).

[25] Almjasheva O.V., Smirnov A.V., Fedorov B.A., Tomkovich M.V., Gusarov V.V. Structural features of $\mathrm{ZrO}_{2}-\mathrm{Y}_{2} \mathrm{O}_{3}$ and $\mathrm{ZrO}_{2}-\mathrm{Gd}_{2} \mathrm{O}_{3}$ nanoparticles formed under hydrothermal conditions. Russ. J. Gen. Chem., 2014, 84(5), P. 804-809.

[26] Smirnov A.V., Fedorov B.A., Tomkovich M.V., Almjasheva O.V., Gusarov V.V. Core-shell nanoparticles forming in the $\mathrm{ZrO}_{2}-\mathrm{Gd}_{2} \mathrm{O}_{3}-\mathrm{H}_{2} \mathrm{O}$ system under hydrothermal conditions. Dokl. Phys. Chem., 2014, 456(1), P. 71-73.

[27] Rusanov A.I. Phase equilibria and surface phenomena. Khimiya, Leningrad, 1967. 388 p. (in Russian).

[28] Gusarov V.V., Suvorov S.A. Thickness of 2-dimensional nonautonomous phases in local equilibrium polycrystalline systems based on a single bulk phase. Russ. J. Appl. Chem., 1993, 66(7), P. 1212-1216.

[29] Pozhidaeva O.V., Korytkova E.N., Romanov D.P., Gusarov V.V. Formation of $\mathrm{ZrO}_{2}$ nanocrystals in hydrothermal media of various chemical compositions. Russ. J. Gen. Chem., 2002, 72(6), P. 849-853.

[30] Almjasheva O.V. Formation and structural transformations of nanoparticles in the $\mathrm{TiO}_{2}-\mathrm{H}_{2} \mathrm{O}$ system. Nanosyst.: Phys. Chem. Math., 2016, 7(6), P. 1031-1049.

[31] Ivanov V.K., Fedorov P.P., Baranchikov A.Y., Osiko V.V. Oriented attachment of particles: 100 years of investigations of non-classical crystal growth. Russ. Chem. Rev., 2014, 83(12), P. 1204-1222.

[32] Fedorov P.P., Ivanov V.K. Cooperative Formation of Crystals by Aggregation and Intergrowth of Nanoparticles. Dokl. Phys., 56(4), P. 205-207.

[33] Suvorov S.A., Semin E.G., Gusarov V.V. Phase Diagrams and Thermodynamics of Oxide Solid Solutions. Leningrad University, Leningrad, 1986. 140 p. (in Russian).

[34] Urusov V.S. Theory of Isomorphic Mixing. Science, Moscow, 1977, 251 p. (in Russian).

[35] Landau L.D., Lifshitz E.M. Theoretical Physics. Statistical Physics. (vol. V). Part I. 3-rd ed., Rev. M.: Science. Ch. Ed. Fiz.-Mat. Lit, 1976, 584 p. (in Russian).

[36] Degtyarev S.A., Voronin G.F. Solution of ill-posed problems in thermodynamics of phase equilibria. $\mathrm{The}_{\mathrm{ZrO}}-\mathrm{Y}_{2} \mathrm{O}_{3}$ system. Calphad, $1988,12(1)$, P. $73-82$. 